\title{
Quality lines
}

doi:10.1136/qshc.2009.036996

The natural history of recovery for the "second victim" of a medical error

When a medical error occurs, regardless of system defects that might underlie such an error, healthcare professionals frequently feel that they have personally failed their patient or failed to competently apply their caring professional skills. Some have called these health professionals the "second victims" of medical errors, in addition to the harmed patient and family. In this report from the US, findings from semistructured interviews of 31 second victims identified 6 stages that delineate the natural history of recovery for second victims. The stages were similar regardless of profession or gender. They are characterised as 1) chaos and accident response; 2) intensive reflection; 3) restoration of personal integrity; 4) enduring the inquisition; 5) obtaining personal first aid; and 6) moving on. Many second victims found benefit from more active participation in healthcare improvement work. The authors suggest that institutions might implement strategies to support and hasten progression through the 6 stages. An accompanying commentary explores the moral imperative for organizations to address medical errors both proactively, as a preventive strategy, but also after the occurrence of such an event.

See page 323 and page 325

\section{Risk of injury for healthcare} personnel who work night shifts and long hours

Conventional wisdom suggests that working long hour schedules or unconventional shifts impair job performance of healthcare workers, with obvious implications for patient safety and the quality of care. Working in such health care settingssettings characterised by fatiguing or unusual schedules - might make health workers more susceptible to illnesses or to injuries on the job. A report in this issue of QSHC explores the risks that are faced by health care workers in a variety of job schedules involving long hours, overtime, night shifts, rotating shifts, and other scheduling arrangements. The results suggest that overtime schedules or schedules requiring more than 60 hours per week create the greatest danger for job injuries for such healthcare workers. The effects of demanding work

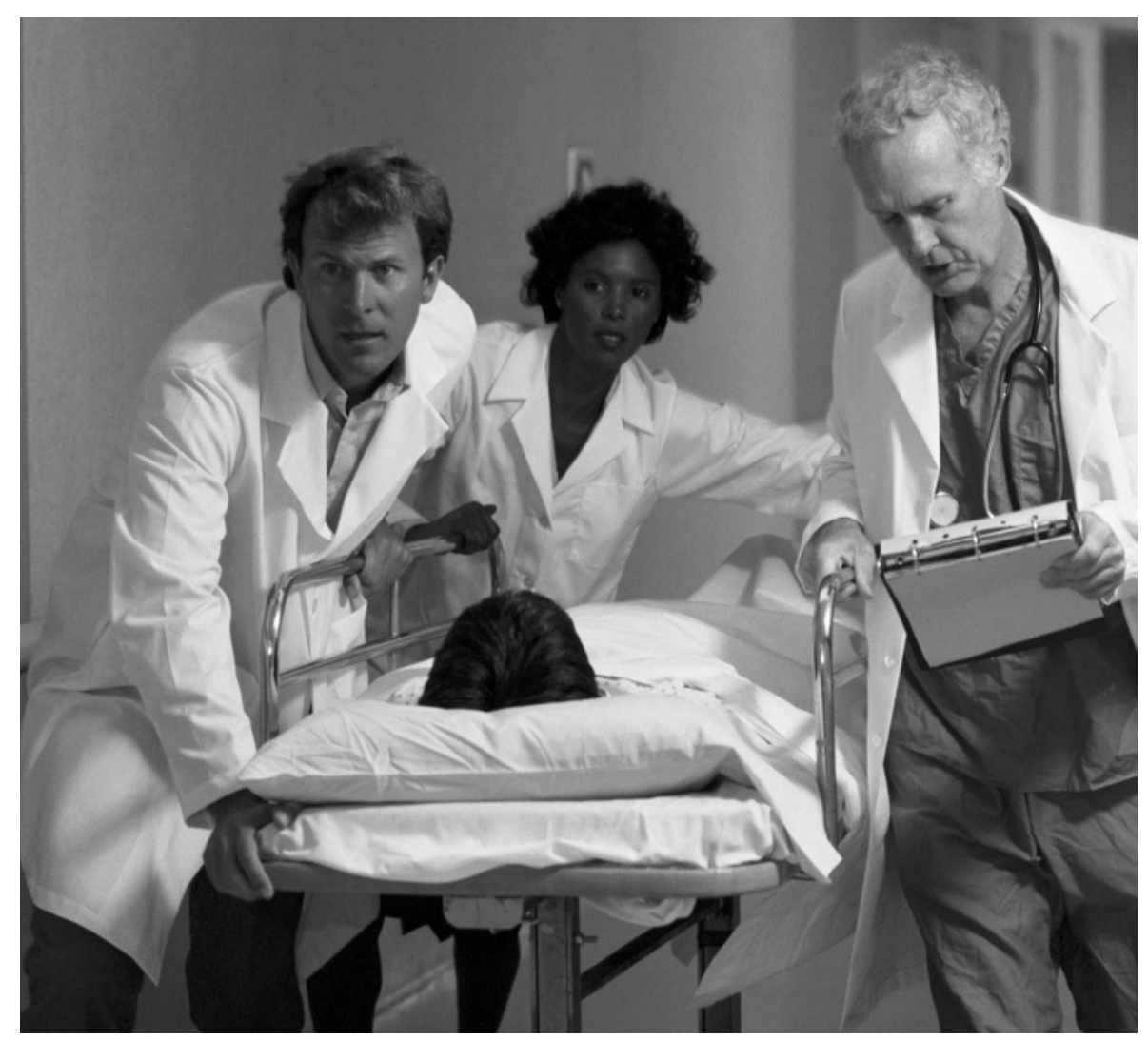

schedules appear to be even more of a concern for support personnel, such as aides, attendants, technicians, therapists, and dieticians, than for nurses and physicians.

$$
\text { See page } 336
$$

\section{Care homes for the elderly need} an integrated strategy to reduce medication errors

A report from the UK shows that 7 out of 10 patients in a care home are subject to some form of medication error. The nature of these errors spreads evenly across prescribing, monitoring, dispensing and administration of medicines. By combining simultaneous quantitative and qualitative methods these authors were able to provide insight into factors that cause the errors, which in turn offer opportunities for solutions. High on the list are the lack of coordination and understanding among the various healthcare professionals-GP practices, pharmacy professionals, and care home staff. Contributing factors included GPs prescribing without access to their computer system, the workload of home staff, inefficient ordering systems and pharmacies that did not know the needs of the homes. The authors conclude there is a need for leadership to create better integrated professional practices among all care components. See page 341

\section{Heroes and martyrs: the role of} Frank and Lillian Gilbreth in bringing systematic management to the operating theatre

The popular Heroes and martyrs series returns to QSHC in this issue. The advent of scientific management in operating rooms at the beginning of the $20^{\text {th }}$ century included pioneering research of Frank and Lillian Gilbreth's studies of work flows and processes. Gilbreth developed many of his early theories and techniques while working as a building contractor. Such an approach, when applied to surgical settings, focused on motion study and standardization of procedures. Applying the precepts of management as a science led to standardization, greater efficiency and ultimately to better surgical outcomes. See page 413 